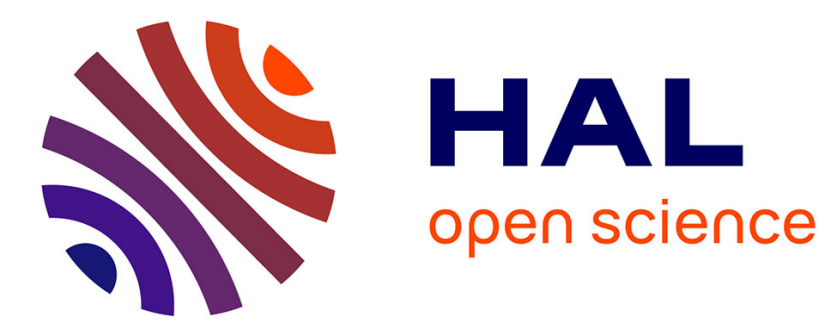

\title{
Tang Dynasty Aesthetic Criteria: Zhang Huaiguan's Shuduan
}

\author{
Yolaine Escande
}

\section{To cite this version:}

Yolaine Escande. Tang Dynasty Aesthetic Criteria: Zhang Huaiguan's Shuduan. Journal of Chinese Philosophy, 2014, 41 (1-2), pp.148-169. 10.1111/1540-6253.12093 . hal-02534394

\section{HAL Id: hal-02534394 \\ https://hal.science/hal-02534394}

Submitted on 23 Apr 2020

HAL is a multi-disciplinary open access archive for the deposit and dissemination of scientific research documents, whether they are published or not. The documents may come from teaching and research institutions in France or abroad, or from public or private research centers.
L'archive ouverte pluridisciplinaire HAL, est destinée au dépôt et à la diffusion de documents scientifiques de niveau recherche, publiés ou non, émanant des établissements d'enseignement et de recherche français ou étrangers, des laboratoires publics ou privés. 
Yolaine ESCANDE: “Tang Dynasty Aesthetic Criteria: Zhang Huaiguan's Shuduan”, Journal of Chinese Philosophy, vol. 41, issue 1-2, march-June 2014, pp. 148-169.

http://onlinelibrary.wiley.com/doi/10.1111/1540-6253.12093/abstract

YOLAINE ESCANDE

\title{
TANG DYNASTY AESTHETIC CRITERIA: ZHANG HUAIGUAN'S SHUDUAN ${ }^{1}$
}

\begin{abstract}
The Shuduan 《書斷》 (Judgments on Calligraphers) by Zhang Huaiguan of the Tang dynasty comprises classifications of calligraphy that Chinese theoreticians still refer to. This article aims at considering the functioning and efficacy of such evaluations through a study comparing this work to other treatises and, when relevant, to the European tradition. Its main objective is to examine how Chinese aesthetic theory responded to new evaluative needs that appeared during this crucial period in Chinese history. Thus, it seeks to clarify the nature of the criteria adopted by Zhang Huaiguan for his gradings: are they material, ideological, aesthetic, or of another nature?
\end{abstract}

The treatise Shuduan 《書斷》(Judgments on Calligraphers) com- posed during the Tang dynasty by Zhang Huaiguan 張懷瓘 (active ca. 724-760) comprises classifications (pin 品) of calligraphy that Chinese theoreticians still refer to. The theory concerning this art differs in many respects from that applied to Western arts. First, it concerns practices not, or rarely found in the West, such as the art of writing, commonly translated by "calligraphy," or ink painting. When the Chinese tradition offers a theorization of an artistic activity that exists in the West, literature or poetry for instance, problems arise if one tries to translate or understand such theorization, which belongs to a spe- cific register of Chinese literary art. It also reflects certain general characteristics of Chinese thought: classifications, lists, rankings are to be found everywhere in Chinese texts. Though they have excited the curiosity of writers such as Jorge Luis Borges or Michel Foucault, ${ }^{2}$ they are not often studied as objects in themselves. ${ }^{3}$ They seem to reflect a need for hierarchization, from a cosmogonic and political viewpoint.

Zhang Huaiguan's theoretical work allows us to apprehend con- cretely the functioning of a ranking system for calligraphy, considered

YOLAINE ESCANDE, Research Director, Centre for Research on Arts and Languages (CRAL); French National Centre for Scientific Research (CNRS). Specialties: Chinese aesthetics and theory of arts, calligraphy and painting. E-mail: yolesc@ehess.fr 
ZHANG HUAIGUAN'S SHUDUAN 149

as China's "high" art, at a period - the Tang dynasty - when the prac- tice and theory of this art were blooming. It is then that Chinese calli- graphic scripts were codified. Zhang Huaiguan's texts probably fulfilled the theoretical needs of his time, since the great art theoreti- cian Zhang Yanyuan 張 $\square$ 元 (810?-880?) included six of his writings in his Fashu Yaolu 《法書要錄》(Essentials of Calligraphy). ${ }^{4}$ Later, Zhang Huaiguan's contribution to calligraphy was compared to that of Zhang Yanyuan to in the field of painting. ${ }^{5}$ Zhang Huaiguan's biography is not included in the two histories of the Tang dynasty, and only Zhu Changwen 朱長文 (1039-1098), a Song dynasty theoretician, mentions a few details about him: ${ }^{6}$ Zhang, active between 724 and 760 , faithfully served the dynasty as an official, even during An Lush- an's rebellion (703-757), and, as a Hanlin academician, he had access to a number of genuine artworks. He was not a pure theoretician since, according to Zhu Changwen, he considered himself a good calligrapher.

The Shuduan belongs to a tradition of classifications and evalua- tions that was highly developed under the Tang dynasty, and has been perpetuated ever since, and which will be presented below. In this study, we will be led to ask how Chinese aesthetic theory responded to the need for such evaluation. It will question Zhang Huaiguan's choice of criteria: are they purely aesthetic, for example, without any material or ideological considerations? Do they belong to an elaborated theory that could be termed "aesthetic" as in Western treatises? Before that, a short introduction to the research in this field and some definitions seem indispensible.

\section{Overview of the Ranking Tradition and Some Definitions}

Chinese art theory belongs to a specific tradition in the appreciation and evaluation of artworks and artists, one closely related to the centuries-old practice of judging and ranking human beings, especially officials. As pointed out by John Timothy Wixted in "The Nature of Evaluation in the Shih-p'in (Grading of Poets) by Chung Hung (469 BCE2518 CE),', 7 between the Han and Wei-Jin Periods (second-fifth centuries), artists - calligraphers, poets and painters - were ranked in several degrees. Wixted analyzes the main origins of the grading of poets in three degrees, which derives from the chapter entitled “Gujin Ren Biao'” $h$ 古今人表i (Table of Men Past and Present) in the Hanshu (Han History) by Ban Gu (32-92 CE), in which officials are classified in three grades (shang 上, zhong 中, xia 下). These classifications were probably established in order to determine the suitability of 


\section{YOLAINE ESCANDE}

individuals for particular functions. Other specific treatises on the evaluation of chess players, painters, etc., are mentioned by Wixted, but he does not examine the meanings of the word pin.

In fact, in the commentary in the Hanshu, pin is used with the same sense as in treatises on art: "Pin means to organize into a hierarchy (dengcha 等差). ${ }^{, 8}$ During the Three Kingdoms Period (220-280) the “nine classes" (jiupin 九品) system was established, 9 based on a hier- archy of candidates to officialdom. This ranking was constituted of three classes - superior, average, and inferior (shang, zhong, xia) - themselves subdivided in three degrees: shang, zhong, xia. The term pin, closely related to the principle of recommendation for the selec- tion of officials, was quite broad and had several meanings: “to judge, evaluate” (pinping 品評), “to appreciate” (pinzao 品藻), “to deter- mine” (pinjian 品鑒), and “to classify” (chapin 差品). This system of recommendation was replaced by imperial examinations in $583,{ }^{10}$ and under the Tang dynasty officials were also ranked in nine degrees. Hence, pin concerns an evaluation of men based on their capacities; it means "to appreciate" as well as "to classify," in the language of the administration and in the arts.

In theoretical treatises, the gradings (pin) in three degrees are sometimes named descriptively, which represents a kind of definition: thus, there is a correspondence between the higher degree, shang, and the class called shen 神 (divine, inspired), between the average degree, zhong, and the miao 妙 (marvelous) class, and last between the lowest degree, xia, and the neng 能 (competent, talented) class. Moreover, each of these grades is further subdivided into three degrees (shang, zhong, xia).

Zhang Huaiguan from the Tang dynasty is not the first art theoreti- cian to propose a methodical, ordered ranking of calligraphers. But he stands out as an innovator because his gradings are founded on value criteria which he himself formulates - although he does not clearly define the terms he uses (shen, miao, neng) - and because they are implicitly linked to traditional degree rankings (shang, zhong, xia). He also innovates in subdividing each class by calligraphic script. Several of his essays are extant, and they can be found in Zhang Yanyuan's Fashu yaolu.

The first writer to classify calligraphic works is Yu Jianwu 座肩吾 (487-551), in a single chapter of his Shupin 《書品》(Classification of Calligraphers), ${ }^{11}$ during a period when there was a burgeoning of ranking treatises in several fields (chess, poetry, painting). $\mathrm{Yu}$ lists 123 calligraphers from Han to Liang in nine degrees, from superior- superior (shang zhi shang 上之上) to inferior-inferior, including in order, superior-average (shang zhi zhong), superior-inferior (shang zhi xia 上之下), etc. Yu compares one calligrapher to another, returns 


\section{ZHANG HUAIGUAN'S SHUDUAN 151}

to the origin of their styles and determines hierarchies. Zhang Zhi 張芝 (?-192), Zhong You 鍾缶 (151-230), and Wang Xizhi 王羲之 (303-361) are ranked in the superiorsuperior degree. Yu Jianwu cre- ates a model of calligraphic grading, taking as norms “"naturalness, spontaneity” (tianran 天然) and "work, effort” (gongfu 功夫):

For Zhang (Zhi), effort comes first, then spontaneity; for Zhong (You), it is spontaneity first, then effort. Wang (Xizhi) is not Zhang's equal in effort, but he surpasses him in spontaneity. ${ }^{12}$

Thus, Yu founds the basis of calligraphic theory by citing his main references and establishing a nine-degree hierarchy based on the lat- ter. A century later, following Yu's model, Li Sizhen 李思貞 (?-696) composes the Shupin Hou《書品後》 (Classification of Calligraphers Continuation). He ranks eighty-two calligraphers, beginning with Li Si 李 斯 (284-208 BCE) who is not included in the classification as he is judged superior to the others; why, one might wonder, are the gradings not used to classify calligraphers? This issue will be examined later.

However, three great early Tang calligraphers, Ouyang Xun 歐陽詢 (557-641), Yu Shinan 䖒世南 (558-638), and Chu Suiliang 褚隨良 (596-658), are ranked as shang-xia pin, that is, in the third of the nine classes. Shupin hou's originality lies in a tenth class, added to the now traditional nine degrees: the yi 逸 class is ranked between Li Si and the superior-superior degree. This is the only class given a designation by Li Sizhen: yi here means "without constraints." It includes "unclassi- fied" artists - who nevertheless are less "unclassifiable"' than Li Si - that is, Zhang Zhi, Zhong You, and Wang Xizhi and his son, Wang Xianzhi 王獻之 (344-386).For each of the above, the author specifies the calligraphic forms in which they excel, and adds a laudatory appreciation. In his classifica- tion, Li Sizhen determines each calligrapher's qualities and points out their differences; moreover, he compares them and studies the origins of their styles. In his work, which is more elaborated and complex than Yu Jianwu's, pin has the two meanings: "hierarchy"' and "criticism, evaluation."

The eighth-century writer, Zhang Huaiguan takes over the tradi- tional three-degree classification (shang, zhong, xia) in several of his treatises, and adopts a matching system of three classes (shen, miao, neng), each of which is subdivided into various calligraphic styles (seal, regular, cursive scripts, etc.). But he does not retain the yi class in the Shuduan or in any of his other treatises.

The late-Tang dynasty author Zhu Jingxuan 朱景玄 (the ninth century) applies classifications from the Shuduan to painting in his Tang-chao Minghua Lu《唐朝名畫錄 》) (Annals of Renowned Tang Painters). But he also adopts the "unclassifiable"' artist class (yi). 


\section{YOLAINE ESCANDE}

Hence, the pictorial field comprises four grades instead of three, and pictorial theory, thus, establishes the classificatory tradition which is still perpetuated today.

Last, in the field of calligraphy, Zhu Changwen composes the Xu Shuduan 《續書斷》 (Judgments on Calligraphers Continuation), dur- ing the Song dynasty. Extending the work of Zhang Huaiguan, he rates eighty-two calligraphers according to three degrees (shen, miao, neng), beginning with Tang dynasty artists.

\section{Zhang Huaiguan's Criteria in the SHUGU and the SHUDUAN}

The intimate links existing between the grading of officials and that of artists lead us to question the relationship between art, politics and ideology, even before mentioning aesthetic criteria, especially as these rankings relate to artists, but not artworks, although these artworks are viewed, studied and copied by generations of literati, and bought by collectors and art dealers. Therefore, we shall first study the mate- rial aspect of these works.

In order to understand Zhang Huaiguan's evaluation criteria, we shall refer to two of his treatises: the Shugu 《書估》(Market Estima- tion of Calligraphers), dated 754, and the famous Shuduan, dated $724-727 .{ }^{13}$ We will first examine the homogeneity of these texts which will allow us to shed light on them from a methodological perspective, drawing from the one to elucidate the other. This will then allow us to determine Zhang Huaiguan's implicit or explicit grading criteria, that is, his material, spiritual, ideological, or aesthetic criteria.

\section{The Issue of the Material Criterion}

Today, the Shugu is considered a unique text in the history of calligra- phy, one "without antecedent or continuation": its author wrote it, so he said, "for pleasure," as explained by the editors of the Anthology of Suc- cessive Dynasties' Treatises on Calligraphy, ${ }^{14}$ minimizing its importance. In fact, as Hsiung Ping-Ming states, the Shugu "deals with the market value of famous calligraphers' artworks,", and he translates its title as "The Commercial Valuation of Calligraphy" $;{ }^{16}$ such mercantile reflec- tions certainly do not correspond to the image that literati would like to project of themselves. Yet, this treatise is of great value, and its validity should not be underestimated, as Zhang Yanyuan considered it impor- tant enough to be included in his Fashu Yaolu. Theoreticians of calligra- phy generally do not ignore it - in fact, this text can be compared to the Shuduan and its criteria are identical, as we shall now see. Further, the 


\section{ZHANG HUAIGUAN'S SHUDUAN 153}

Shugu offers almost the same classifications as the Shuduan: the same calligraphers (seventy-four instead of ninety-four) are listed, ranked in chronological order both in three main classes - shang, zhong, xia in the Shugu and shen, miao, neng in the Shuduan - and by script.

At the beginning of the treatise, Zhang Huaiguan states:

Some young amateurs would like to know more about famous callig- raphies since Antiquity, and they absolutely would like to determine their different rankings, arguing this helps their knowledge of callig- raphy. In the red (brush) on white (sheet of paper dansu, i.e., calligra- phy), tastes differ, people's likes or dislikes are rarely identical. If an evaluation is not perfectly thorough, everyone obstinately digs his heels in, and, consequently, opinions throughout the world are plenti- ful and confused. Why not state clearly one's criteria and not leave others in any doubt? Indeed these young men appreciate my doing so; I have been touched by their remarks, and thanks to these evalua- tions, I have distinguished what is valuable from what is cheap, and have highlighted what is good and what is bad. That is why I have taken into account the simple opinions of the world, and I have cho- sen Wang Xizhi as the norm. For instance, in Wang's authentic cur- sive script, 150 characters have the same value as a column in semi- cursive script. But three semi-cursive script columns cost as much as one column in regular script. That is the way we count for an incom- plete manuscript. As for the collected manuscripts ... they are considered the country's treasures, there is no point in trying to calculate their value according to the number of characters.

Recently, (a high official) ... spent hundreds of thousands of strings of cash on just five sheets in Wang Xizhi's semi-cursive, but he could not obtain even one character in regular script. As for the works of Cui Yuan (77-143) and Zhang Zhi, being too rare, they are all kept in the Imperial Library. ${ }^{17}$

First, Zhang Huaiguan justifies his gradings by the requirements of the times, along with the demand from art lovers and people who want to buy calligraphies on the "market." 18 He chooses as a norm the most commonly held opinion, and delimits certain criteria which he later explicates, taking Wang Xizhi as his reference. When one wants to buy calligraphies on the market, Zhang warns, there are no more good works available, because most of the genuine works are kept in the Imperial Library, and even a very rich buyer would find it impossible to obtain a single character of Wang Xizhi's regular script. The basic price of a calligraphy is determined by counting the characters, in col- umns, Zhang says; the price also depends on the style (Wang Xizhi's regular script is more expensive than his cursive), and Zhang does not give any absolute values or prices. This method of determining the cost of calligraphic artwork has remained unchanged to this day.

Yet, second, he sets out three degrees of market evaluation (sangu 三估), each comprising five levels (wudeng 五等), from the best to the 


\section{YOLAINE ESCANDE}

less good, that is, from most expensive to cheapest (guijian shupin 貴 賤殊品), the bestthe most expensive-being the most ancient (shanggu 上估), which means Shizhou's seal script. The second degree in his evaluation is represented by Zhong You and Zhang Zhi; and the third degree, by more recent calligraphers, although still considered ancient: the two Wangs. We will see below that Wang Xizhi fulfills the role of calligraphic norm and market benchmark with a particular script; hence the norm is a calligrapher belonging to the third degree (xiagu 下估). These three evaluative degrees, entitled shanggu, zhonggu, and xiagu, replace the traditional three-classes hierarchy (shang, zhong, xiapin). The term gu 估, used alone, means " to esti- mate (a price), to calculate (the price)"; gu, therefore, is a grammatical equivalent to pin while semantically it insists on the market value.

But, unexpectedly, it should be noted that these three evaluative degrees have to be considered as idealizations since, except for Wang Xizhi's cursive script, which is the one taken as the norm, the above calligraphers' artworks cannot actually be found on the market. Some manuscripts, instead of gu 估, “evaluate," quote the term gu 古, " "ancient.." Thus, though these criteria are effectively ideal, that is, immaterial, Zhang Huaiguan still speculates about their price in one particular case - that of Wang Xizhi. In other terms, although the cri- terion is ideal, there is or there can be no effective purchase or sale corresponding to this criterion.

In sum, if Shizhou's works in seal script correspond to the best, it is because they are the most ancient: "The ancient is expensive, the recent is cheap," Zhang further explains. Consequently, the primary artistic and market value criterion of a calligraphy is clearly its antiqueness: the older, the more expensive. As Zhang Huaiguan was a calligrapher, an expert, and an academician, his opinions are not purely fantasy, or dis- connected from the concerns of artists. Under the Tang dynasty, it was common for market value to serve as a reference for aesthetic value. For instance, the New Tang History describes how the youthful Chu Suiliang asked his master, Yu Shinan, what was the value of his calligraphy compared to that of Zhiyong (the sixth century). Yu replied: "I heard each of his characters costs 50,000 strings of cash; how could you get yours up to that level?,${ }^{20}$ Here, the criterion of aesthetic apprecia- tion is considered in relation to market value, though $\mathrm{Yu}$ Shinan was himself a calligrapher, and has been a model, that is, an artistic norm, ever since the Tang dynasty. Hence, Zhang Huaiguan's criteria must be quite emblematic of the "orthodox" thought of his time.

The use of antiqueness as a market value criterion is not an exclu- sively Chinese practice: the Western tradition also recognizes a similar criterion. The differences are their uses: Zhang Huaiguan does not consider the price of the artwork as less important than its aesthetic 


\section{ZHANG HUAIGUAN'S SHUDUAN 155}

value, and of course the two are not antagonistic. Clearly, here, the aesthetic value, market value and conception of the artwork go together, whereas in the Western tradition this is not at all self-evi- dent. ${ }^{21}$ Note that this conception is still current among today's Chinese literati: it is usual and natural in explicit or implicit gradings to evalu- ate an artist according to the going rate for his/her calligraphies, depending on the number of characters and on the type of script.

Nevertheless, while scholars today still follow these grading prac- tices, art theory never explicitly refers to material or mercantile crite- ria, unlike Zhang Huaiguan's texts. On this point, "modern', Chinese art theory, that is, since the Qing dynasty and up to today, can be com- pared to that of the West. Jean-Marie Schaeffer has pointed out that in Western Europe and North America, it appears that the loss of art's functional (religious, didactic, ethical) legitimacy has created a void into which philosophy has fallen. Art and philosophy seem to be fight- ing a common enemy: mundane reality and the material considera- tions that result from it. ${ }^{22}$ Thus, there is a gap between theory - what art critics and artists assert - and practice, depending on market real- ities and on social, pictorial or even political constraints, such as social status or artistic trends. ${ }^{23}$ Consequently, art and market value are opposed to each other and considered contradictory. ${ }^{24}$

The link between material market value and aesthetic value is self- evident in Zhang Huaiguan's treatise, and belongs to the definition of the artwork under the Tang dynasty. The reason why this link is later forgotten or concealed, at least in theoretical texts, may be related to the specific theoretically amateurish and disinterested conception of art developed by the literati tradition, especially since its ideal reinter- pretation by Dong Qichang (1555-1636) in the Ming dynasty.

But as regards Zhang Huaiguan's Shugu, how should we under- stand the relationship between the three evaluative degrees (sangu) and five levels (wudeng) Zhang mentions after his introduction? He lists five levels of calligraphers, ranging from those whose prices are equal to Wang Xizhi's and Wang Xianzhi's up to early Tang dynasty calligraphers. In the following excerpt, we see that the second eval- uation criterion is the degree of integration into the style of the model:

First level: nine calligraphers:

Historiographer of Yellow Emperor, historiographer of Zhou Xuan, Zhong You, Zhang Zhi, Wang Xizhi, Cui Yuan, Wei Guan (third century), Suo Jing (third century), Wang Xianzhi.

Second level: six calligraphers:

Cai Yong (132-192), Zhang Chang (second century), Xun Xu (third century), Huang Xiang (second century), Wei Dan (active 227-239), Zhong Hui (225-264). 
http://onlinelibrary.wiley.com/doi/10.1111/1540-6253.12093/abstract

\section{YOLAINE ESCANDE}

Compared to Cui Yuan and Zhang Zhi, their moral value is inferior. Their market value is slightly lower than that of Wang Xizhi's semi- cursive script.

Third level: forty-three calligraphers (comprising) Liu Desheng (sec- ond century). . .

Some of these, whose scrolls are visible, are extraordinarily talented. Others' (works) are difficult to find or have disappeared. Some have the same value as Wang Xizhi's cursive script.

Fourth level: twenty-nine calligraphers (including) Xiao Ziliang (fifth century).

Their talent is more or less noteworthy. Sometimes, one of them can be excellent. If we take the average, their wisdom and their strength being homogenous, (their calligraphy) can be worth one third of the value of Wang Xizhi's cursive script value.

Fifth level: nine calligraphers:(. . ) Zhiyong (sixth century), Yu Shinan, Ouyang Xun, Chu Suiliang.

(Their calligraphy) can be worth one quarter of the value of Wang Xizhi's cursive script. ${ }^{25}$

The calligraphers are generally presented in chronological order, except the two Wangs, ranked at level one because they are the refer- ences. The closest to Zhang chronologically are ranked at level five. The most valuable style is Wang Xizhi's semicursive script, then comes his cursive script; regular script is not mentioned because it is no longer available on the market. Zhang continues:

Even though their quality is globally similar, what is rare is expensive. Our contemporaries are graceful, the Ancients elegant. The ancient is expensive, the recent is cheap. ${ }^{26}$

Hence, though the "quality is similar,' as far as the intrinsic and aesthetic value of these calligraphers is concerned, what makes the dif- ference is their availability or absence from the market, that is, their rarity. Zhang explains further:

I have divided (the calligraphers) into three evaluative degrees (sangu), based on their spiritual and formal filiations. I have ranked them in five levels (wudeng) depending on their different market values. ${ }^{27}$

"Spiritual and formal filiations"' and "elegant" Ancients allude to the Ancients' moral qualities, considered superior to those of the Moderns - another commonplace under the Tang dynasty. ${ }^{28}$ Hence, the three evaluative degrees (sangu) concern antiqueness, while the five levels (wudeng) depend on market value, determined by the price for characters in a specific style (Wang Xizhi's cursive script) by the model calligrapher. Zhang Huaiguan's treatise offers two different levels of reading, just as in the Shuduan. But he also points out that he 


\section{ZHANG HUAIGUAN'S SHUDUAN 157}

has only listed the best calligraphers and has not been influenced by rumor. ${ }^{29}$

Thus, the work that Zhang goes on to produce is that of a connois- seur and art historian: he determines the best calligraphers, according to their price and aesthetic quality, by comparison with a stylistic model serving as a reference. Unfortunately, no genuine manuscript by the stylistic model, the calligrapher Wang Xizhi, is extant, even though he still serves as a model in the apprenticeship of calligraphy today, especially in semicursive script. On the other hand, we can still admire works by fifth-level artists, Zhiyong, Yu Shinan, Ouyang Xun, and Chu Suiliang whose calligraphy is valued at a quarter of Wang Xizhi's cursive script. All four remain models, especially for regular script. Note that $\mathrm{Yu}$, Ouyang, and Chu were ordered by the emperor Taizong (r. 626-649) to copy Wang Xizhi's masterpieces for posterity.

Zhang Huaiguan never describes any artwork, nor cites any; he is only interested in what the artist represents. Nevertheless, dealers and collectors unquestionably buy artworks. Market value appears to be directly related to antiqueness, rarity, and the artist's moral value - it seems that the more ancient he is, the greater the moral value he acquires. The importance attached by Zhang to antiqueness is not spe-cific to him, and he is emblematic of his time: the calligrapher and the- oretician Sun Guoting (625?-695? or 648?-702?) describes in his Shupu 《書譜》 (Treatise on Calligraphy, 687) how he transformed his own work, that formerly had not attracted the interest of experts, into "venerable", artwork by making it look antique. ${ }^{30}$ Unlike Tang dynasty art theory, the evaluation of Western art concerns the artwork itself, which is traditionally described, commented on, analyzed, and whose effect on the spectator - its affective impression - is meticu- lously reported. ${ }^{31}$ Aesthetics itself appears to be mainly a theory of perception, that is, an analysis of the artwork's reception. Western aes- thetic categories - the beautiful, the ugly, the sublime, the gracious, the tragic...-apply to artworks, criticism is concerned with the art- works, and theory with the works and not their authors. The norms for these categories were originally intimately related to canons of corpo- ral beauty, representing a microcosm of the divine world since the Renaissance. ${ }^{32}$ According to this conception, Western critics and theo- reticians of art have tried to establish objective criteria for the evalua- tion of works of art. As, in contrast, the Chinese art tradition is centered not on the object but on the human being who produces it, how is it, one may ask, that a material criterion has become decisive in evaluation?

It should be noted that Zhang Huaiguan's gradings are patently not purely aesthetic. But for those who consider that utility or function refer to pragmatic instrumentality and material needs, a concept such 


\section{YOLAINE ESCANDE}

as functional or practical value cannot serve as an aesthetic value. ${ }^{33}$ However, Zhang Huaiguan's treatises express the opposite position. As a "classical" Chinese theoretician-because he has become a ref- erence-Zhang takes different criteria into account without excluding some in favor of others, whereas "classical" or even modern Western critics generally define aesthetic value as being opposed to other sour- ces of interest: hedonistic, playful, practical, sentimental, decorative, historical, ideological, etc. In other words, in this last perspective, the "essential value" - but is there an "essential" value in art? - of an art- work may not reside in what is usually used to distinguish and to classify. 34

\section{The Criteria and Classification System of the SHUDUAN}

The Shuduan shares with the Shugu the same criteria of antiqueness and rarity, but as it is much more complex and elaborated, it requires a brief introduction.

After a preface in which Zhang explains the genesis of the written character, he traces the origin and evolution of ten scripts 35 and gives an appreciation of them: each will be taken as a category with which to rank calligraphers. Then, he meticulously grades each calligrapher by script and by class (shen, miao, neng) before giving their biographies.

Zhang considers that almost all the scripts have a human origin. When retained in the Shuduan's rankings, the creator of each script is systematically classed as shen for the form he invented: thus, the antiqueness criterion determines his ranking. Then, follow the names of those who have brought a script to perfection. Liu Desheng, how- ever, is an exception: although he "initiated semi-cursive script,"' he is ranked in the third class, miao, as in the Shugu, where he is graded at the third level, with calligraphers whose scripts cost a little less than Wang Xizhi's cursive.

Zhang Huaiguan innovates in the Shuduan by providing all the his- torical sources available at his time and comparing them systemati- cally. But he remains absolutely "orthodox" in attributing the origin of each script to a creator, an important figure and often a scholar. This creator initiates a practice and establishes a continuity chain to which, generally speaking, the artists continuously refer.

After this historical section, Zhang classifies the calligraphers in three gradings: shen, miao, neng, each of them subdivided by script. First, as he classifies artists rather than artworks, some calligraphers are ranked shen in one script and miao or neng in others. Such is the case of Wang Xianzhi, graded neng (competent) for his bafen, and shen (divine, inspired) for his lishu, xingshu, zhangcao, feibai, and 


\section{ZHANG HUAIGUAN'S SHUDUAN 159}

caoshu. But, from an aesthetic point of view, can a calligrapher main- tain a constant level not only in one script but in others? From a mar- ket viewpoint, does that mean all the work of a calligrapher has the same market value in a single script, irrespective of when it was cre- ated? Zhang answers this last question in the Shugu, when he explains that "what is rare is expensive": Wang Xizhi's works are rare, and whatever the script they were written in, they are necessarily expen- sive. Consequently, even if an artist's artworks have all been bought up, as all his calligraphies have the same value, the gradings given by Zhang Huaiguan mean that we have an idea of the person concerned, and they also mean that the market value is artificial: it is simply a cri- terion which is generally accepted and easy to understand, whose pur- pose is to clarify the workings of the classification. The veritable standard is not monetary but human; in other words, the role of the material criterion is to convey an immaterial value. This point was explained earlier by Zhang in the Shugu: "I have distinguished what is valuable from what is cheap, and I have highlighted what is good and what is bad.',

In the third section, Zhang inserts a short biography of each callig- rapher. He only ranks those who were no longer alive in 727, when he finished writing the Shuduan. Perhaps it is because Zhang Xu 張旭 (675?-759?) and Yan Zhenqing 顏真卿 (709-785) were still alive that he did not classify them. Here again, the most important criterion seems to be antiqueness. We should note the difference with Zhu Changwen from the Song dynasty: though a follower of Zhang, Zhu does not hesitate to rank one of his famous contemporaries, Cai Xiang 蔡襄 (1012-1067), in the miao class, and to grade Ancients such as Han Yu 韓愈 (768-824) - in the neng class - among the Moderns, along with Cai Xiang. This brief example shows how criteria evolve under the different dynasties and explains one of the difficulties in studying such gradings. While the terms do not change, their meaning is modified as the evaluation criteria are different.

Thus, in the Shuduan and the Shugu, the criterion of antiqueness is essential, but on condition that the artworks of the ranked calligra- phers have a commercial value on the market, that is, are available and are rare. This criterion of antiqueness, therefore, is in practice ideal, since the market or material value of an artwork corresponds to the moral or spiritual value of its author, as indicated in his biography. Before going any further, it is useful to recall that reference to the Ancients, which means to Antiquity and to ancient authors, is also a question dealt with in European art theory. For instance, Renaissance artists and theoreticians, such as Leon Battista Alberti, reinterpreted the texts of Greek antiquity, in order to create an ideal image of the artist, more concerned with glory than with money, and with 


\section{YOLAINE ESCANDE}

distinguishing himself from the common craftsman. ${ }^{36}$ Even though ancient art remains a source of inspiration, and though Antiquity is a constant reference for European artists and theoreticians, as it is for their Chinese counterparts, the development of Western art is envis- aged as progress, a notion that does not exist in the Chinese tradition. That is why Modern artists, in the classical European conception, can generally be considered superior to the Ancients, ${ }^{37}$ something, that is, unthinkable in Tang China.

\section{The Issue of the Ideological Criterion}

In the Chinese literati tradition, understood in the broad sense, art, which is theoretically considered as a pastime or leisure activity, is used by the ruling power as an instrument of legitimization. As Simon Leys has pointed out, the status of art is largely founded on its role as guarantor of political legitimacy, based on political and religious power. ${ }^{38}$ Indeed, one expression of the link between politics, ideology, the market, and art is obvious in the tradition of the ranking of artists. What follows may help in understanding this aspect of Chinese aes- thetic appreciation.

As we have seen, Chinese art theory is preoccupied with the model artist rather than with artworks, which only count if they embody spir- itual qualities, related to what is represented by antiqueness. These qualities are somehow gradable in a work's selling or purchase price. Nevertheless, the ideological criterion is important too.

Zhang Huaiguan, for his part, seemingly takes Wang Xizhi as an aesthetic reference. But in fact, this model of reference was first recog- nized and established by the greatest Tang dynasty emperor, Taizong (r. 626-649). During Taizong's reign, Wang Xizhi who was already famous but who had not yet become a reference in calligraphy like Zhang Zhi or Zhong You, began to be immensely admired. Taizong sought out genuine works by the Master all over the empire, had them authenticated by Imperial Library experts, and ultimately was buried together with the greatest Masterpiece of Chinese "high" art, the famous Lanting Xu 《蘭亭序》(Preface to the Orchid Pavilion). ${ }^{39}$ Wang Xizhi's calligraphic style contributed to the symbolic unification of the empire, as he represented the Southern tradition, the guardian of Han culture, whereas the Tang dynasty came from a Northern "bar- barian" culture. ${ }^{40}$ Artworks by the two Wangs were collected by Southern dynasties, and the contents of the Imperial Library of the Chen dynasty (557589) ${ }^{41}$ were absorbed into those of the Sui and then the Tang dynasties. On the other hand, the evaluation of Wang Xizhi's regular script corresponds to the general normalization that occurs in calligraphy during that period: early Tang dynasty 


\section{ZHANG HUAIGUAN'S SHUDUAN 161}

calligraphers formulate a codification of regular script that has not changed since then. 42 Thus, this script has a central position as a crite- rion of judgment in the examination system. It also enters the recently opened imperial schools and acquires the status of official script, and serves to strengthen and legitimize the ruling power. ${ }^{43}$ From an ideological and political standpoint, Wang Xizhi's regular script is the sym- bol and expression of the new power. Moreover, for the first time, Wang Xizhi's manuscripts are carved in stone and also printed, by order of Taizong. 44 The choice of this calligrapher was no accident. First, he is the model par excellence both as official and man: born into an aristocratic family, he became a high civil and military officer, and behaved, therefore, as an accomplished Confucian. But he was also a practicing Daoist, a disciple of the “Dao of Five Pecks of Rice", (Wudoumi Dao 五鬥米道) sect, and was able to avoid being influ- enced in his art by the political power thanks to his extreme creative freedom. Second, Taizong whose family name was Li, could trace his lineage to Laozi, ${ }^{45}$ and his greatly admired calligraphic freedom. Wang Xizhi was the perfect embodiment of the ideology and institu- tional power of the Tang dynasty. The norm chosen by Zhang Huaiguan is not without significance: it is not the "simple opinions of the world," but a reference imposed by the central authority that Zhang merely adopts.

This is probably one of the reasons why the critic does not need to describe the artworks. Therefore, the problem of objective evaluation, as conceptualized and aspired to in Europe, is avoided. Here, consid- erable attention is focused on the subject, who is himself representa- tive of the orthodoxy in place. Thus, we can consider this theory of art with its ideal of objectivity does not deal any better with the issue of evaluation, ${ }^{46}$ as it ignores or eludes it. At all events, the problem is posed in different terms. In the Shuduan, material data are not ignored, they are integrated into the appreciation and taken for granted, together with certain ideological or spiritual-moral considera- tions. The description of the artwork is not important since an artist's calligraphies are all considered as having the same qualities, from the viewpoint of the "moral value" of their author. Accordingly, as the available artworks are rare, there is actually no choice.

Indeed, while Zhang Huaiguan clearly explains the relation between his judgments and the constraints of the society of his time, he is also well aware of their limits, as he puts it in the Shugu:

As for Wang Xizhi, his regular script is supremely marvelous. He counts a great deal in society, therefore his market value is equal to that of average degree (zhonggu) calligraphers. Cui Yuan, Zhang Zhi represent jade; Wang Xizhi gold. Great merchants attach importance to jade; small storekeepers value gold. Superficial people mainly rely 


\section{YOLAINE ESCANDE}

on rumor, for them Wang's calligraphy is the best, whether in regular or cursive script, indifferently. How could they appreciate the value of Wang Xizhi's calligraphy? In fact, there are five levels. ${ }^{47}$

Zhang is conscious he has to satisfy two requirements: market value, which everyone is aware of, and aesthetic value, which "small storekeepers" do not understand. Zhang rejects no one, he adapts by creating two standards of classification: the three evaluative (market) degrees (sangu) and the levels (wudeng) that allow evaluation based on a norm of prestige recognizable by all, that is, the calligraphy of Wang Xizhi. Zhang's objective is not to exclude anyone, nor to claim possession of the truth; his is a purely utilitarian aim, which is, it should not be forgotten, the prior justification for evaluation or classification. In other words, from a functionalist point of view, Zhang's gradings are justified by their functional utility, in other terms, they are practi- cal and didactic. Zhang addresses both connoisseurs (great merchants) and "storekeepers," two worlds that, elsewhere, seem to be antinomic. ${ }^{48}$

\section{The Issue of the Aesthetic Criterion}

Antiqueness and market value are not the only criteria Zhang takes into account: aesthetic value is also important! But here again, artistic value is not everything, because it is disputable, as he explained earlier in the Shugu: "In calligraphy, tastes differ, (...) consequently, opin- ions in the world are plentiful and confused." The selected calligrapher also needs to be a model, which is the main rule governing his choice: "That is why I have taken into account the simple opinions of the world, and I have chosen Wang Xizhi as a norm."'

The specificity of the Shuduan compared to Zhang's other texts and to those of other theoreticians, is that the artists are ranked not only by script, but also in new classes that include the type of script: shen, miao, and neng. On the one hand, we find lists of calligraphers' names, and on the other, a "description" in metaphorical terms of their art. We know these classifications have a didactic objective, as Zhang refers to Confucius' Analects in his Preface. But then questions arise: how are the metaphorical expressions to be understood? and is it nec- essary to grasp the meaning of Zhang's gradings? Moreover, the shen, miao, and neng classes do not actually seem to be defined. Does this mean that for a Tang dynasty reader the meanings of these classes were self-evident? Presumably, they were not particularly clear, as lit- tle more than fifty years later, the theoretician Dou Meng 竇蒙 (active ca. 742-756) in his Shushu fu《述書賦》(Poem on Calligraphy, 775), felt it necessary to define Tang dynasty aesthetic terms: 


\section{ZHANG HUAIGUAN'S SHUDUAN 163}

Shen: it can not be reached intentionally, but can be conceived. Neng: able to master all scripts. Miao: having a multitude of shades and savors. ${ }^{49}$

Let us return to Zhang's own explanations. After the name list and before the biographies, he writes of the three classes:

I have included above the Ancient and the Modern, without exceeding three classes. The skillful and the awkward are ranked in order, without exceeding a few hundred calligraphers. Miao aspires to shen; but one who walks cannot gallop. Neng hopes to become miao, but follows the rules excessively. In each script, I have ranked the good and the less good, and I have allocated each of them to his appropriate class. ${ }^{50}$

Zhang justifies his classifications by their concision: in all, three classes, instead of nine for his predecessors. Moreover, they have a meaning: they indicate different degrees of value, the best or highest is called shen. Zhang continues:

As for the shen class, Li Si, Du Du (first century), Cui Yuan, Huang Xiang (second century), Wei Guan (third century), Suo Jing (first century), alone are ranked first. Shizhou, Cai Yong, Zhong You are ranked second. Zhang Zhi is ranked third, Wang Xizhi and Wang Xianzhi fourth and fifth. 51

Here, Zhang presents a value ranking from the best to the least good in the superior class, and in one specific script. He goes on:

When one examines the various classes ranked above, few calligra- phers obtain a grading in the miao class, and even less in the shen. Moreover, the differences between superior and inferior are clearly apparent, and for the rest as well. The biographies that follow are listed in chronological order. $^{52}$

Zhang acknowledges that the gradings within each script category are ranked in chronological order. Does this mean, therefore, that he refrains from offering an aesthetic appreciation? In fact, if such an appreciation is absent, it suggests the reader should give one of his own. In other words, in order to determine the aesthetic difference between the good and the less good, one needs to be an insider. Last, he explains:

Sometimes, names are included despite the fact that I have not been able to appreciate the traces of their brushes (see their calligraphies); generally, for the Ancients, I have indicated what is transmitted about them, and, for the Moderns, if their calligraphy has disappeared, I have studied them globally; in order to list them in the classifications, I have only inquired about their original biography, that is all. ${ }^{53}$

From all the above, we can deduce that the Shuduan offers two clas- sifications with different standards, as does the Shugu: the three classes (shen, miao, neng) that indicate different degrees of quality, 


\section{YOLAINE ESCANDE}

depending on aesthetic value and market price, and the script catego- ries, in which the artists are ranked in chronological order.

\section{The Aesthetic Criterion in a Specific Script}

Let us now examine how the Shuduan deals with a specific script in one of the three classes. We will take the superior class, and the script that Zhang seems to appreciate particularly - given the extent of his praise for it - the cursive script, cao.

In the preface to the Shuduan, Zhang Huaiguan explains the crea- tive process behind socalled shen artwork, but in terms that do not appear to correspond to the definition of a value criterion. ${ }^{54}$ Rather, they represent metaphorical praise of shen artwork that pertains to the spontaneous nature of its emergence. Once again, the Shugu allows a practical explanation to be found. The quality criterion applied to the two Wangs in the Shugu is: “They stand alone in his- tory" (qiangu duli 前古獨立), ${ }^{55}$ which is to say, they have created an original form. Thus, for Zhang Huaiguan, Wang Xizhi renewed zhang cursive script, which is why he and his son can be "taken as models for hundreds of generations." ${ }^{56}$ Indeed, in the Shuduan, the criteria that are most often used to "describe" shen class calligraphers are: “vari- ety” (bian 變or gai 改), “creation” (chuang 創), “becoming one's own school” (zi cheng yijia 自成一家). For instance, he writes:

_ Li Si: "He transformed" (gai zhi 改之).

_ Du Du: "He created its divine and marvelous (expression)" (chuang qi shen miao 創其神妙);

_ “He was unmatched" (du bu 獨步).

_ Zhang Zhi: “He created"' (you chuang 又創);

_ “The changes (in his brushstrokes) are innumerable” (bian- hua zhi ji 變化之極

$\overline{1}$.

_ Cai Yong: “Hundreds of changes”' (bai bian 百變);

_ “He created" (you chuang 又創).

_ Wang Xizhi: “He did not care about trends” (bu gu changliu 不顧常流);

_ “He became his own school” (zi cheng yijia fa 自成一家法);

_ “A multitude of changes" (qian bian wan hua 千變萬化).

_ Wang Xianzhi: “He created his own technique” (bie chuang qi fa 別創其法).

_ Huang Xiang: “In each script he achieved perfection”' (ge zao qi ji 各造其極

). ${ }^{57}$ Though these criteria are not exclusive, they highlight at least one requirement: novelty. All the artists ranked as shen are either 


\section{ZHANG HUAIGUAN'S SHUDUAN 165}

inventors or transformers. Thus, though Chinese art theory reveres the ancient, it by no means rejects originality. However, the originality that goes with creating one's own school differs from individual origi- nality. In the apprenticeship of calligraphy, one has first to study a script, which means a specific model in a specific style. Therefore, the beginner in calligraphy has to choose a "school." In other terms, what counts in the recognition of a model, is the use made of it as a model. Thus, the calligrapher is not appreciated strictly for his own sake, but for "the school" he creates, that is, his calligraphic style, one that will be studied for generations.

\section{Conclusion}

We can conclude that Chinese art theory does indeed involve an esthetic reflection on evaluation, but its aim differs from that of West- ern art theory in that it focuses on the subject and not the object; it has as its reference a "model'" unanimously recognized at a given period. In the case of Zhang Huaiguan's Shuduan, we have distinguished sev- eral levels of understanding. Using a structuralist terminology, we can say that Zhang's classifications may be read according to two systems: one is syntagmatic, with the shen class as the superior norm, which is not defined a priori. The other is paradigmatic, and it takes an insider to comprehend its logic: only those who have studied the history of calligraphy and copied the models can completely grasp its subtlety. For it is by copying a master, and performing identical brushstrokes gestures, that one assimilate the former's human qualities, and becomes him for the duration of the brushstroke. Therefore, the qual- ities one looks for in a model depend on each individual's personality, which is why Zhang Huaiguan leaves the reader to interpret as he/she wishes the artistic quality of the models he lists.

In the syntagmatic system, there are three aspects to evaluation:

1.Stylistic: this ranking is deliberately chosen by Zhang in response to a practical need (such as that of art dealers) as in each script, calligraphers are ranked in chronological order;

2. Chronological: the gradings match criteria of price and antiqueness, and enable the reader to easily understand the logic of the text;

3. Qualitative: this grading is solely denotative, it presumes to take into account originality in a given script, and, as we have seen, the main criterion for the shen class is novelty. 


\section{YOLAINE ESCANDE}

In the paradigmatic system, the most important consideration for Zhang is to respond to the reader's needs. Thus, he does not give an a priori grading, but enables the reader to be quickly aware of the ranked calligraphers' most highly appreciated scripts, and to learn about their personal qualities in their biographies. The reader is informed of the moral qualities of the model he wants to choose, and also learns in which scripts these qualities are best expressed.

Zhang Huaiguan probably wrote a text that corresponded to his time representing, according to Liang Yan 粱镉 (eighteenth century), “the Tang dynasty's honored method" (Tang shang fa 唐賞法). ${ }^{58}$ Thanks to Zhang's qualitative classification by script, the user, the connoisseur or the art dealer had at his disposal a handbook of the best calligraphers in all styles. Moreover, his work has the virtue of shedding new light on his predecessors; it helps us understand Yu Jianwu or Li Sizhen's classifications, which appear strange because they were insufficiently elaborated. These classifications resulted from the fact that their authors could not place at the same level artists whose works were totally impossible to find, artists serving as norms or models for their contemporaries, and other artists. They either avoided the problem-like Yu Jianwu, who does not mention the Ancients and who ranks the calligraphers taken as norms in the supe- rior class-or they leave them aside-like Li Sizhen, who removes Li Si from the gradings, and considers the model calligraphers, the two Wangs, as norms for the rankings. Zhang Huaiguan offers a much more complex classification that takes into account all these different factors. This is probably why his work is still a reference today.

For Westerners, the limit of this kind of evaluation is that it does not provide any tangible information on the artworks themselves, which were bought by dealers and collectors, or on the choice of artists in his rankings, who were all dead by the time Zhang wrote the Shu- duan. For a Tang dynasty calligrapher, art dealer, or connoisseur, however, this treatise would probably have been easy to understand. Though it is important to recall that the evaluation criteria under the Tang dynasty differ from those of other periods in China, as we have pointed out with reference to the Song dynasty.

However, the study of Zhang's criteria reveals some general charac- teristics of Chinese art theory, for it is a real theory, a structured reflec- tion with didactic, social, aesthetic, or even political objectives. These Chinese classifications differ profoundly from their Western counter- parts. In the West, the art critic or connoisseur focuses on the value of the object, and hence evaluates an artwork, seeking a spiritual value in a physical object, sometimes referred to as the "essence" of art. In contrast, the immediate interest of the Chinese theoretician is the spir- itual value - at once aesthetic, ethical, and ideologicalof the artist 


\section{ZHANG HUAIGUAN'S SHUDUAN 167}

he declares to be a "model,', and whose artworks come to represent the artistic norm. Such human value is no obstacle to an artwork's market value. It is merely a matter of two different levels in the approach to art.

The main interest in the study of the functioning of classification in a Chinese theoretical text on art lies in pointing out its specificities, which might at first glance seem illogical or absurd, but which is defi- nitely not the case. Conversely, they prove useful in a specific context. For Zhang is writing simultaneously for art experts, connoisseurs, that is, insiders and literati, but also simple storekeepers, people who do not appreciate art in the same way at all. Thus, the main virtue of Zhang's treatise is that it shows us an effective classification system for all kinds of readers, and is recognized as such.

CENTRE FOR RESEARCH ON ARTS AND LANGUAGES FRENCH NATIONAL CENTRE FOR SCIENTIFIC RESEARCH Paris, France

\section{Endnotes}

Acknowledgment of Legal Copyrights and Intellectual Credentials:

I would like to express my gratitude to the Editor-in-Chief, Chung-ying Cheng, for invit- ing me to participate this special issue, and to this issue Editor, Timothy Connolly, for his support.

1. This article is a substantially revised version of an article entitled "Classements et évaluations dans la calligraphie chinoise, á partir du Shuduan de Zhang Huaiguan,' E' tudes chinoises 16, no. 2 (1997): 39-113.

2. Jorge Luis Borges, 'El idioma analitico de John Wilkins,' in Otras inquisiciones (Buenos Aires: Emecé Editores, 1960), 139-44, quoted by Michel Foucault in his pref- ace to The Order of Things: An Archaeology of the Human Sciences, trans. Alan Sheri- dan (New York: Vintage Books, 1970), xv, originally published as Les Mots et les choses (Paris: Gallimard, 1966).

3. Exceptinthe' "Effetsd'ordredanslacivilisationchinoise.Rangementsàl'œuvre,clas- sifications implicites,' special issue, Extrême-Orient-Extrême-Occident 10 (1988). 
http://onlinelibrary.wiley.com/doi/10.1111/1540-6253.12093/abstract

4.Zhang Yanyuan, considered the Tang dynasty's greatest theoretician, is the author of Lidai Minghua Ji《歷代名畫記》(Annals of Famous Painters of Successive Dynas- ties, 847) and Fashu Yaolu.

5. See William R. B. Acker's translation of Zhang Yanyuan's Lidai Minghua Ji in Some T'ang and Pre-T’ang Texts on Chinese Painting, 2 vols. (Leiden: E. J. Brill, 1954 and 1974).

6. Huang Jian, ed., Lidai Shufa Lunwen Xuan (An Anthology of Successive Dynasties' Treatises on Calligraphy) (Shanghai: Shuhua Chubanshe, 1979), 344.

7.In Susan Bush and Christian Murch, eds., Theories of the Arts in China (Princeton: Princeton University Press 1983), 225-64.

8. Hanshu(Beijing:ZhonghuaShuju,1962),94A,3773(cmt.4).

9. See Henri Maspero and Etienne Balazs, Histoire et institutions de la Chine ancienne (Paris: P.U.F., 1967), 116-17.

10. SeeDenisTwitchettandJohnFairbank,eds.,SuiandT'angChina,Vol.3ofTheCam- bridge History of China (Cambridge: Cambridge University Press, 1979), 91-92.

11. ZhangHuaiguan'streatisesareavailableinacollection:AnAnthologyofTreatiseson Calligraphy of Successive Dynasties (Shanghai: Shuhua Chubanshe, 1979), 144-233;

\section{YOLAINE ESCANDE}

those of Yu Jianwu, 85-91. See also Zhang Yanyuan's Fashu Yaolu (Essentials of Cal- ligraphy) (Beijing: Renmin Meishu Chubanshe, 1986); Zhang Huaiguan, Juan 4, 139-165, and Juan 7, 8, 9. Yu Jianwu, Shupin Juan 2, 61-74.

12. Huang,LidaiShufaLunwenXuan,87.Unlessotherwisenoted,alltranslationsaremy own.

13. Allinibid.

14. Ibid.,143.

15. Zhongguo Shufa Lilun Tixi (The Theoretical Systems in Chinese Calligraphy) (Hong Kong: Shangwu, 1984), 165.

16. InFrench:“'Évaluationcommercialedelacalligraphie,' 'inZhangXuetlacalligraphie cursive folle (Paris: IDHEC, 1984), 31.

17. Huang,LidaiShufaLunwenXuan,150.

18. Actually, what I refer to here as the art "market"' cannot be compared to today's financial markets with their fluctuating exchange rates.

19. ThisisthecasewithZhang YanyuanFashuYaolu,140.

Yolaine ESCANDE: “Tang Dynasty Aesthetic Criteria: Zhang Huaiguan's Shuduan”, Journal of Chinese Philosophy, vol. 41, issue 1-2, march-June 2014, pp. 148-169. 
20. OuyangXiuXinTangshu198,5646.

21. See Jean-Marie Schaeffer, Les Célibataires de l'art: Pour une esthétique sans mythes (Paris: Gallimard, 1996), especially 13-18, 23, 24, 250.

22. J.-M. Schaeffer, Art of the Modern Age: Philosophy of Art from Kant to Heidegger (Princeton: Princeton University Press, 2000), trans. Stephen Rendall, originally pub- lished as L'Art de l'a^ge moderne: L'esthétique et la philosophie de l'art du XVIIIe siecle a' nos jours (Paris: Gallimard, 1992), introduction and Chap. 5,

23. See Pierre Bourdieu, "La production de la croyance: Contribution à une économie des biens symboliques," Actes de la recherche en sciences sociales no. 13 (1977): 3-40, more especially 4, 29-30, trans. Richard Nice as "The Production of Belief: Contribu- tion to an Economy of Symbolic Goods," Media, Culture and Society 2 (1980): 261-93.

24. SeeMarcSchell,Art\&Money(Chicago:UniversityofChicagoPress,1995).

25. Huang,LidaiShufaLunwenXuan,151-53.

26. Ibid.,153.

27. Ibid.,151.

28. See, for instance, Sun Guoting (625?-695? or 648?-702?), Shupu (Treatise on Calligraphy, 687), trans. Chang Ch'ung-ho and Hans H. Frankel, Two Chinese Treatises on Calligraphy (New Haven: Yale University Press, 1995), 1.

29. Huang,LidaiShufaLunwenXuan,153.

30. SeeChangandFrankel,TwoTreatisesonCalligraphy,15.

31. See, for instance, Michael Fried, Absorption and Theatricality: Painting and Beholder in the Age of Diderot (Berkeley: University of California Press, 1980).

32. See Jacqueline Lichtenstein's introduction to beauty in J. Lichtenstein, ed., Textes essentiels sur la peinture (Paris: Larousse, 1995), 193-97.

33. SeeP.Bourdieu, "TheProductionofBelief:ContributiontoanEconomyofSymbolic Goods"; Michel Freitag, "Notes pour une sociologie de l'art," Sociologie de l'art 4 (1991): 33-35, $39-41$.

34. See J.-M. Schaeffer, L'Art de l'a^ge moderne and Les Ce' libataires de l'art, 13-18, $23,24,250$.

35. These are: antique script (guwen 古文), great seal (dazhuan 大管), Zhou script (Zhou wen 籀文), small seal (xiaozhuan 小篦), eight tenths (bafen 八分), clerical script (lishu 隸書), draft cursive script (zhangcao 章草), semi-cursive script (xingshu 行書), flying- white (feibai飛白), and cursive script (caoshu 草書).

Yolaine ESCANDE: “Tang Dynasty Aesthetic Criteria: Zhang Huaiguan's Shuduan”, Journal of Chinese Philosophy, vol. 41, issue 1-2, march-June 2014, pp. 148-169. 
36. See Leon Battista Alberti, On Painting, trans. John R. Spencer (New Haven: Yale University Press, 1956), 3: 52.

37. See, for instance, Giorgio Vasari (1511-1574), Lives of the Most Excellent Painters, Sculptors and Architects, trans. Gaston Du C. De Vere, 10 vols. (London: Macmillan \& The Medici Society, 1912-14). This author demonstrates, in Vol. 1, how Giotto (1266?1336), and in Vol. 5, how Leonardo da Vinci (1452-1519) created model art- works as the outcome of continuous progress in art.

38. See Simon Leys (alias of Pierre Ryckmans), 'L'attitude des Chinois à l'égard du passé,' Commentaire 10 (1987): 447-57, especially 451.

\section{ZHANG HUAIGUAN'S SHUDUAN 169}

39. SeeS.Leys, “L'attitudedesChinois,’’456.

40. See John Curtis Perry and Bardwell L. Smith, eds., Essays on T'ang Society (Leiden: E. J. Brill, 1976), 1-3.

41. The calligrapher and theoretician Yu He (active 465-471) relates how dozens of the two Wangs' works were admired, collected and mounted on scrolls under the Liu Song dynasty (420-479), in his Lunshu Biao (On Calligraphy, 470), Lidai Shufa Lun- wen Xuan, 51-53.

42. Stephen J. Goldberg, "Court Calligraphy of the Early Tang Dynasty,' Artibus Asiae 49, no. 3-4 (1988-89): 189-237, especially 198-202.

43. Ibid. See also Yao Xuexian, "Tang Taizong yu Shufa', (Tang Taizong and Calligraphy), Zhengzhou Daxue Xuebao 2 (April 1986): 98-102.

44. See Lothar Ledderose, Mi Fu and the Classical Tradition of Chinese Calligraphy, (Princeton: Princeton University Press, 1979), 36.

45. See Arthur F. Wright, “'T'ang T'ai-tsung and Buddhism,'” in Arthur F. Wright and Denis Twitchett, eds., Perspectives on the T'ang (New Haven: Yale University Press, 1973), 251-52.

46. On the issue of the limits of evaluation with a view to objectivity, see J.-M. Schaeffer, L'Artdel'a^gemoderne, andLesCe' libatairesdel'art.

47. Huang,LidaiShufaLunwenXuan,151.

48. SeeJ.-M.Schaeffer,LesCe' libatairesdel'art,56-57.

49. InZhangYanyuanFashuYaolu,216;Huang,LidaiShufaLunwenXuan,266.

50. Huang,LidaiShufaLunwenXuan,174.

Yolaine ESCANDE: “Tang Dynasty Aesthetic Criteria: Zhang Huaiguan's Shuduan”, Journal of Chinese Philosophy, vol. 41, issue 1-2, march-June 2014, pp. 148-169. 
51. Ibid.,174-75.

52. Ibid.,175,emphasisadded.

53. Ibid.,175.

54. Ibid.,155.

55. Ibid.,151.

56. Ibid.,151.

57. All these examples can be found in Shuduan, in Huang, Lidai Shufa Lunwen Xuan, 17581.

58. PingShuTie(OntheAppraisalofCalligraphyandLetters),Huang,LidaiShufaLun- wen Xuan, 575. 